\title{
Outpatients' Satisfaction in the Context of 10 Years of Health-Care Reform: A Cross-Sectional Study of Tertiary Hospitals in Shiyan, China
}

This article was published in the following Dove Press journal: Patient Preference and Adherence

\author{
Li Ke $\mathrm{K}^{1,2, *}$ \\ Jingshu Chen ${ }^{3, *}$ \\ Jia Jia ${ }^{1}, *$ \\ Pan $\mathrm{Ke}^{4}$ \\ Xueqin $\mathrm{Chen}^{4}$ \\ Zongfu Mao ${ }^{2}$ \\ Bing Liu ${ }^{3,4}$
}

'School of Nursing, Hubei University of Medicine, Shiyan, People's Republic of China; ${ }^{2}$ Global Health Institute, Wuhan University, Wuhan, People's Republic of China; ${ }^{3}$ School of Public Health and Management, Hubei University of Medicine, Shiyan, People's Republic of China; ${ }^{4}$ Center of Health Administration and Development Studies, Hubei University of Medicine, Shiyan, People's Republic of China

*These authors contributed equally to this work

\begin{abstract}
Purpose: This study aimed to evaluate outpatient satisfaction in tertiary hospitals in Shiyan, China, to predict which items had highest priorities for outpatient satisfaction, and to identify population groups on which the medical institutions should focus.
\end{abstract}

Patients and Methods: A cross-sectional survey was conducted at three tertiary hospitals in Shiyan city of China, from March to June 2018. An 18-item outpatient satisfaction questionnaire was applied. We conducted matrix analysis to describe the distribution of satisfaction score and the degree of influence of the items. Outpatient satisfaction was classified into the lowest and highest groups according to the $80 / 20$ rule. Logistic regression model was used to identify demographic factors which might influence outpatient satisfaction.

Results: A total of 2109 valid questionnaires were completed. The "waiting time", "diagnosis and treatment time" and "medical charges" items showed relatively higher degrees of influence but earned lower levels of satisfaction. Outpatients with a college level or above educational background $(\mathrm{AOR}=1.36,95 \% \mathrm{CI}=1.03-1.79)$ and with a family per-capita monthly income $(\mathrm{FPMI})>7000 \mathrm{CNY}(\mathrm{AOR}=3.30,95 \% \mathrm{CI}=1.60-6.81)$ were more prevalent in the lowest satisfaction group. Outpatients with college level or above education background $(\mathrm{COR}=0.77,95 \% \mathrm{CI}=0.60-0.99)$, FPMI of 3001-5000 $\mathrm{CNY} \quad(\mathrm{AOR}=0.76,95 \%$ $\mathrm{CI}=0.60-0.96)$, non-local residents $(\mathrm{AOR}=1.48,95 \% \mathrm{CI}=1.07-2.04)$, and urban workers with medical insurance $(\mathrm{AOR}=1.74,95 \% \mathrm{CI}=1.27-2.39)$ were more prevalent in the highest satisfaction group.

Conclusion: The survey indicated that "long time to wait for treatment", "short treatment time", and "medical charges too expensive" were the top three aspects that need to be improved with priority by medical institutions. Education level, income level, residence and type of health insurance were the sociodemographic characteristics that significantly affect the outpatient satisfaction in tertiary hospitals. These factors need to be paid more attention by healthcare professionals to improve the patients' satisfaction.

Keywords: outpatients' satisfaction, tertiary hospitals, importance matrix analysis, the 80/20 rule

\section{Introduction}

It is been ten years since the central government of China unveiled a new round of health-care reform plans in $2009 .{ }^{1}$ Both state and local governments had implemented a series of policies, including expanding universal health coverage (UHC), establishing a national essential medicine system, improving primary care, improving the availability of public health services, and piloting public hospital reforms. ${ }^{2-5}$ The implementation of the National Hierarchical Medical System (NHMS) had
Correspondence: Bing Liu

Center of Health Administration and Development Studies, Hubei University of Medicine, 30 South Renmin Road, Shiyan 442000, People's Republic of China

Tel +86 I38 $7277 \quad$ I527

Fax +860719 8892203

Email sy-lb@I26.com 
been pushed ahead, and many relevant policies, including the national general practitioner (GP) system and the twoway referral system, were launched. ${ }^{6-8}$ In this way, the NHMS could improve the accessibility of medical services and the efficiency of medical resource utilization. The aim of these policies is to provide more convenient and affordable medical and health services and to improve healthcare quality, making it more beneficial for the citizens.

Policy makers worldwide are now increasingly preferring using patient-experience data rather than performance indicators to assess the quality of health care services. ${ }^{9}$ Patient experience is the overall satisfaction a patient gets during the course of receiving care or treatment. This satisfaction is viewed by patients subjectively or based on objective facts, and it is a key measurement of the quality of medical service. ${ }^{10}$ There is a substantial quantity of literature on patient satisfaction and what factors can affect the level of it. Recent studies have investigated the inpatient or outpatient satisfaction of primary medical institutions or public hospitals, such as the "National Healthcare Improvement Initiative" assessment survey implemented by the National Health Commission of the People's Republic of China. ${ }^{11-20}$ Other studies on patient satisfaction focus on certain populations, such as cancer patients and surgical patients. ${ }^{21,22}$ Patient satisfaction has been reported to be influenced by many subjective and objective factors, including patient demographic characteristics (age, race, gender, education, and health status), patient expectations, patient trust, patient social functioning, quality of medical service, medical staff, and administrative quality. ${ }^{16,23-28}$

These studies also provided important information for health institutions to improve the quality of medical services. The majority of these studies focused on using patient satisfaction score to evaluate health services quality and explore its influencing factors. However, few studies have directly focused on patient satisfaction. More studies have been conducted in Chinese developed areas such as Shanghai and Beijing. ${ }^{16}$ Studies on major cities in underdeveloped central and western regions, like Shiyan, has not been taken seriously. Shiyan is a city in the northwest of Hubei, China. It is the regional central city adjacent to Hubei, Henan, Shanxi and Chongqing provinces, with $3,466,000$ total registered population at the end of 2018 . There is more than 60 hospitals in Shiyan, including three comprehensive tertiary hospitals, which are representative hospitals in the central and western regions of China. ${ }^{29}$ Thus, this study used the importance matrix analysis model of customer satisfaction to find the specific content of satisfaction and dissatisfaction that was evaluated by outpatients. ${ }^{30}$ At the same time, we analyzed the advantages and weaknesses that affect the patient's medical experience.

In addition, few studies tended to categorize patients according to a certain principle and then analyze their satisfaction. In fact, different populations experience different satisfaction levels with the same medical services. ${ }^{16}$ Hospitals should devote themselves to providing optimal medical services and customized services for individual patients, improving the degree of patient satisfaction and attracting more patients to return visits, which is similar to how companies produce products and provide services to meet the needs of consumers. ${ }^{31}$ However, medical institutions should focus on the most satisfied and the most dissatisfied patients. Therefore, this study identified key population groups by categorizing the outpatients. The patient classification scheme is based on the Pareto Principle, or the $80 / 20$ rule, that employs the following rule of thumb: "the vital few and the trivial many". ${ }^{32}$

\section{Materials and Methods}

\section{Study Design and Sample}

We conducted a cross-sectional questionnaire study at the outpatient's departments of three tertiary level public hospitals in Shiyan: Taihe Hospital, the Renmin Hospital and the Dongfeng General Hospital. Taihe Hospital has 3540 beds, 5000 staff, 81 clinical departments, and received more than 1.99 million outpatient visits in 2018. The Renmin Hospital has 2700 beds, 1500 staff, 49 key clinical departments, and 1.37 million outpatient visits annually. The Dongfeng General Hospital has 1438 beds, 1300 staff, 55 clinical departments, and 0.8 million outpatient visits annually. The three hospitals accept the largest number of patients in the city as well as nearby areas.

According to the total amount of outpatient service and the components of each department provided by the hospital for 3 consecutive days, the total amount of evaluation and the sample distribution of each department were calculated based on the sampling model. The sampling model was calculated according to the following formula:

$$
n=\frac{t^{2} \sigma^{2}}{\Delta_{x}^{2}+\frac{t^{2} \sigma^{2}}{N}}
$$

It was estimated that $\mathrm{N}=1045$, with a $95 \% \mathrm{CI}, \mathrm{t}=1.96$, limit error $(\Delta \mathrm{X})=0.1$ and population variance $(\delta 2=1.82)$. 


\section{Questionnaire}

We used the "Outpatient Satisfaction" questionnaire developed by Chongqing Zhidao Hospital Management Corporation, and the questionnaire was authorized by the corporation. The questionnaire consisted of two parts. Section 1 collected general information from the outpatients (gender, age, education level, marital status, family per-capita monthly income, residence, type of health insurance). Section 2 was composed of 18 items that focused on the outpatient experience and related to consultation, waiting, medical treatment, logistics departments and taking medicine. Each item was assigned a level of 1-5 according to the Likert 5-point subscale, with the choices set as "Very dissatisfied, Dissatisfied, Normal, Satisfied and Very satisfied"; and the higher score indicated a higher patient's evaluation on the hospital services. For the 18 items, the total possible score for patient satisfaction was 90. The Cronbach's alpha coefficient of the questionnaire was 0.930 , and the Cronbach's alpha coefficients of all dimensions ranged from 0.679 to 0.804 .

\section{Data Collection Procedure}

According to the study design, the survey was conducted by independent investigators (third-party evaluation) who were equipped with the online survey system on mobile devices between March and June 2018. Before they began the questionnaire, all participants were briefly told about our study and gave their written informed consent. A convenience consecutive sampling method was adopted. Those outpatients who was unable to complete the questionnaire due to a lack of cognitive function or suffering from a disturbance of consciousness, dementia, or other severe physical disorders were excluded. As we believe that children under 12 years old are mentally immature, and they can not fully understand or complete the questionnaires independently. Hence, they were represented by their legal guardian (ie parents or grandparents).

Participants were asked to answer the questionnaires anonymously and independently based on their own true medical experience and feelings, to avoid bias due to induced prompts by the investigators. However, for some who were unable to complete survey questions independently because of illiteracy or vision problems (especially in elderly outpatients), we employed a rigorously trained and qualified staff of investigators to interview them face to face using a consistent and clear explanation of the survey items. Participants were assured that their privacy was guaranteed to be protected.

\section{Statistical Analysis}

Data analysis was conducted using the SPSS statistical package version 22.0. A descriptive analysis was performed using frequencies and percentages to summarize the respondents' demographic characteristics. The importance matrix analysis model of patient experience was established based on the importance matrix analysis model of customer satisfaction. The degree of influence of each item was calculated through the principal component analysis method. The sum of the degree of influence of the 18 items was equal to 1 . The score of patient satisfaction for each item was taken as the horizontal coordinate and the degree of influence as the vertical coordinate. The mean value of the degree of influence and score of patient satisfaction were taken as the benchmarks. The boundaries were divided into four quadrants to obtain the importance matrix result of the outpatient medical experience. The advantages and weaknesses that affect the patient medical experience could be found according to the situation of each index in the matrix.

Furthermore, we divided the population into the lowest and highest satisfaction groups according to the $80 / 20$ rule. The 80/20 rule states that, for many events, approximately $80 \%$ of the effects come from $20 \%$ of the causes. We believed that the $20 \%$ of patients who gave the highest and lowest satisfaction scores are the target population on whom hospital managers should focus. We selected the populations with the highest and lowest scores. Then, the diverse patient satisfaction in different population subgroups was assessed using binary logistic regression models. Crude odds ratios (CORs) and adjusted odds ratios (AORs) with 95\% confidence intervals (CIs) were obtained from univariate and multivariable logistic regression models, respectively. A p-value of $<5 \%$ was considered statistically significant.

\section{Quality Control}

This study was performed to investigate by "third-party evaluation". The third-party evaluation is the assessment conducted by the third-party organizations that are independent of the government or its departments. The third-party investigators are completely independent of medical institutions and government agencies. They are mainly from professional data companies, market consulting companies or academic institutions. Investigators are not established within the evaluation object, and the investigation was 
conducted in a manner to avoid contact with the hospital staff and to eliminate factors of human interference. ${ }^{33}$ The Center of Health Administration and Development Studies of Hubei University of Medicine was conducted as a thirdparty evaluation institution in the study. We recruited local college students and social part-time staff (who have no direct or indirect contact with hospitals and patients) as third-party investigators to evaluate patient satisfaction in tertiary hospitals in the region. Before the evaluation, the investigators were trained professionally. We also performed a preliminary survey before the formal investigation and then eliminated and revised some items according to the preliminary survey. The mobile device was designed to perform logic checks to identify illogical response and determine completeness of the records. A predefined coding system was embedded using hospital ID, questionnaire category, data acquisition time, and interviewer number as a composite key index for identification of all patient records. Each questionnaire was required to meet the following criteria to be considered valid: it took at least one minute to complete one questionnaire, and three questionnaires took at least ten minutes. The gender of the respondents in obstetrics and gynecology was limited to female, and the pediatric age was limited to under 18 years. The data were locked and stored automatically after the survey was completed.

\section{Ethical Statement}

The procedure of this study, including the consent process for all patients was approved by the Ethics Committee of the Hubei University of Medicine (Approval No. 2017-TH-024). The Ethics Committee approved that children under 12 years old need to be consented and represented by their legal guardian.

Informed consent information was attached on the top of each questionnaire and presented before the surveys. Each patient was allowed to participate in the study after reading the informed consent form and signed to confirm their participation. All the information obtained from the study participants was kept confidential.

\section{Results}

\section{Demographic Information of the}

\section{Participants}

A total of 2268 outpatients participated in our face-to-face interviews, and 2109 valid questionnaires were completed (valid rate $93.0 \%$ ). Among the 2109 outpatients, 39.9\% were male, and $64 \%$ were married. Most of the participants
(88.4\%) were local. The participant education level was classified as junior middle graduate or less, high school or technical secondary school, and college graduate or above; the proportion of participants in each category was $38 \%$, $32.1 \%$ and $29.9 \%$, respectively. The participants with a family per-capita monthly income (FPMI) $\leq 3000 \mathrm{CNY}$ (42.6\%) and 3001-5000 CNY (46.7\%) accounted for the majority of the sample. The largest proportion of the participants had medical insurance for urban residents as their health insurance type $(29.7 \%)$. The demographic information of the survey participants is summarized in Table 1.

\section{Importance Matrix Analysis}

The matrix analysis results found that "the patience of doctors", "patients' privacy protection", "service attitude", "guiding services", "accuracy of guidance facilities", and "waiting order" showed relatively high degrees of

Table I Demographic Information of the Participants ( $N=2109)$

\begin{tabular}{|c|c|c|c|}
\hline Variables & $\begin{array}{l}\text { Demographic } \\
\text { Characteristics }\end{array}$ & $\mathbf{n}$ & $\%$ \\
\hline Gender & $\begin{array}{l}\text { Male } \\
\text { Female }\end{array}$ & $\begin{array}{l}84 \mid \\
\mid 268\end{array}$ & $\begin{array}{l}39.9 \\
60.1\end{array}$ \\
\hline Age(years) & $\begin{array}{l}\leq 18 \\
19-39 \\
40-59 \\
\geq 60\end{array}$ & $\begin{array}{l}435 \\
835 \\
544 \\
295\end{array}$ & $\begin{array}{l}20.6 \\
39.6 \\
25.8 \\
14.0\end{array}$ \\
\hline Education level & $\begin{array}{l}\text { Junior middle graduate or less } \\
\text { High school or technical } \\
\text { secondary school } \\
\text { College graduate or above }\end{array}$ & $\begin{array}{l}801 \\
678 \\
630\end{array}$ & $\begin{array}{l}38.0 \\
32.1 \\
29.9\end{array}$ \\
\hline Marital status & $\begin{array}{l}\text { Married } \\
\text { Unmarried }\end{array}$ & $\begin{array}{l}1349 \\
760\end{array}$ & $\begin{array}{l}64.0 \\
36.0\end{array}$ \\
\hline FPMI(CNY) & $\begin{array}{l}\leq 3000 \\
300 I-5000 \\
500 I-7000 \\
>7000\end{array}$ & $\begin{array}{l}898 \\
985 \\
192 \\
34\end{array}$ & $\begin{array}{l}42.6 \\
46.7 \\
9.1 \\
1.6\end{array}$ \\
\hline Residence & $\begin{array}{l}\text { Local } \\
\text { Nonlocal }\end{array}$ & $\begin{array}{l}1864 \\
245\end{array}$ & $\begin{array}{l}88.4 \\
11.6\end{array}$ \\
\hline $\begin{array}{l}\text { Type of health } \\
\text { insurance }\end{array}$ & $\begin{array}{l}\text { MIUR } \\
\text { MIUW } \\
\text { CMI } \\
\text { Other } \\
\text { No health insurance }\end{array}$ & $\begin{array}{l}626 \\
494 \\
53 \\
304 \\
632\end{array}$ & $\begin{array}{l}29.7 \\
23.4 \\
2.5 \\
14.4 \\
30.0\end{array}$ \\
\hline
\end{tabular}

Abbreviations: FPMI, family per-capita monthly income; MIUR, medical insurance for urban residents; MIUW, medical insurance for urban workers; CMI, commercial medical insurance. 
influence and satisfaction in the matrix. "The waiting time for registration" and "the waiting time for payment" showed a relatively high level of satisfaction. However, "the waiting time of diagnosis and treatment", "the diagnosis and treatment time", "the release of the doctors" attendance information", "medical charges", "the waiting time for getting the medicine" and "the notification of drug usage" showed relatively high weight values but earned low levels of satisfaction. These areas needed urgent improvement by medical institutions. The matrix theory model is shown in Figure 1, and the results of the matrix analysis are shown in Figure 2.

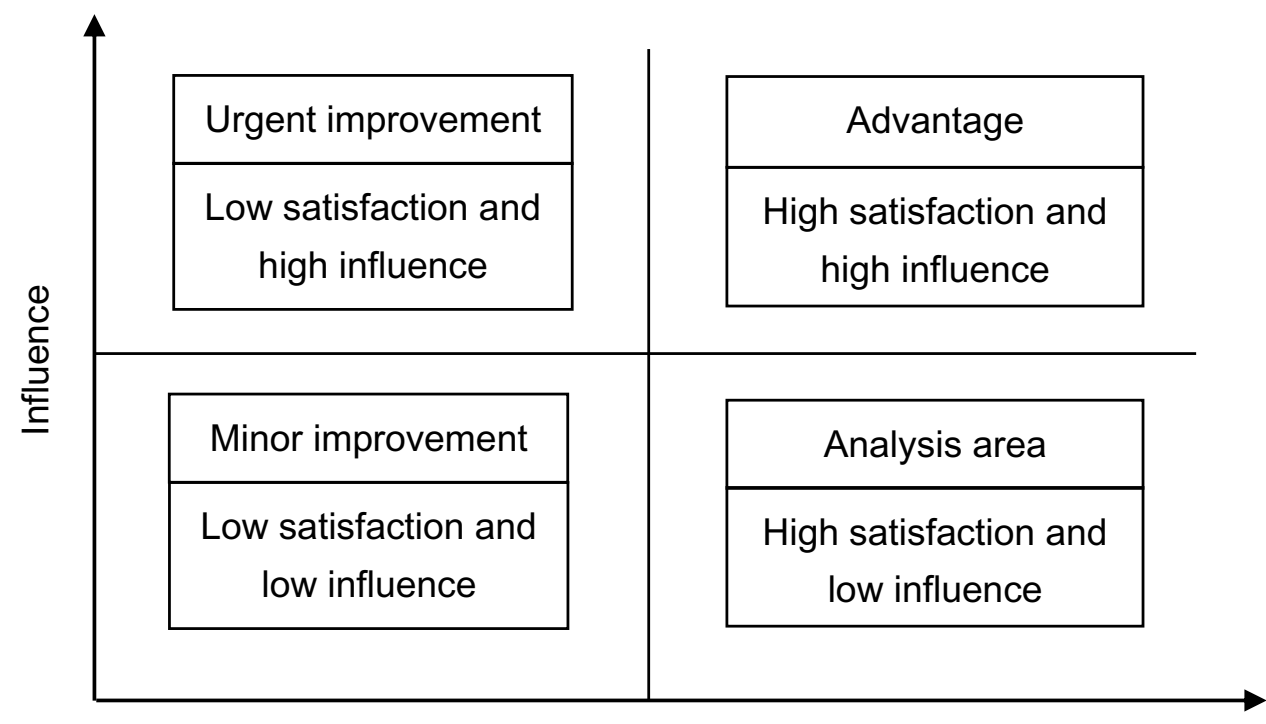

Patient evaluation

Figure I The importance matrix analysis modeling method.

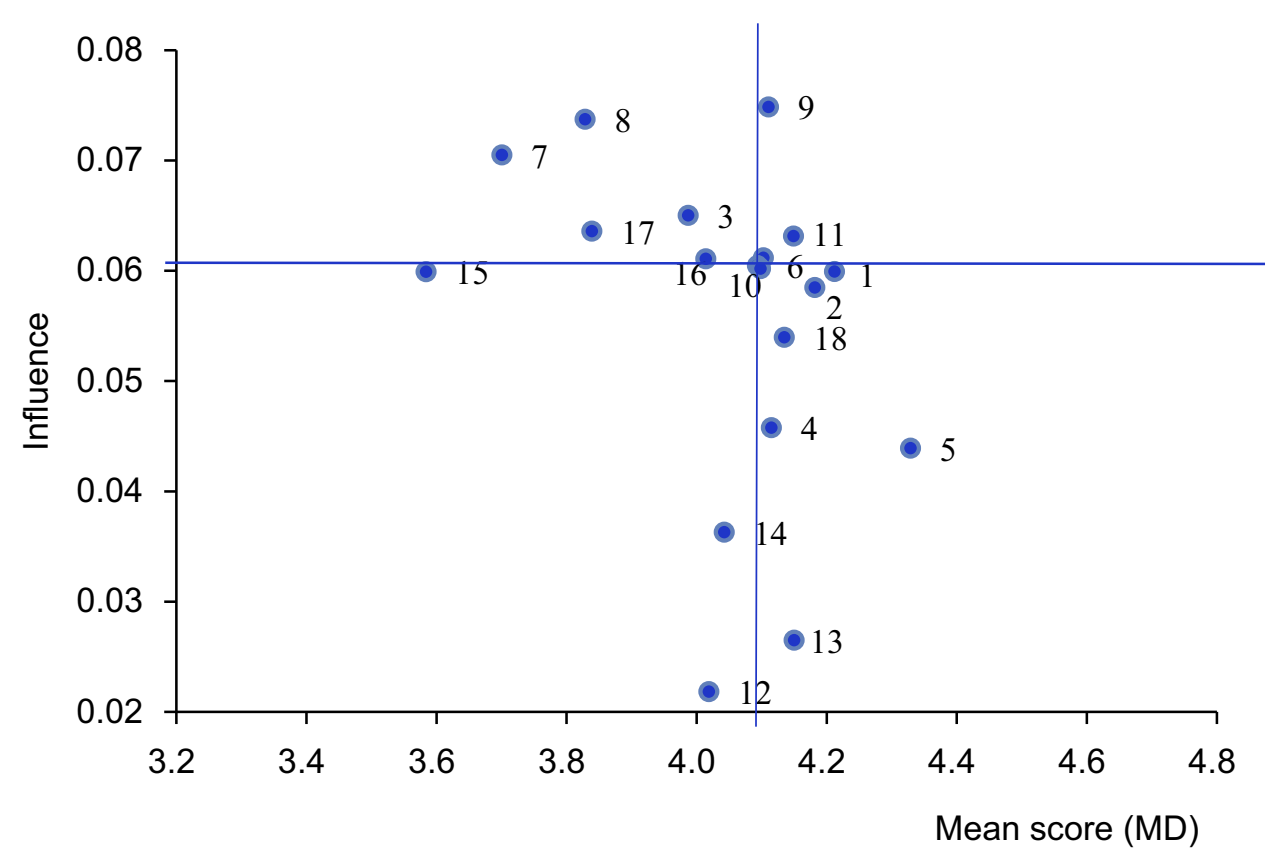

Figure 2 The importance matrix analysis of outpatient satisfaction.

Notes: The median score ( $X=4.10, Y=0.06)$; I guiding services; 2 accuracy of guidance facilities; 3 release of the doctors' attendance information; 4 the waiting time for registration; 5 the waiting time for payment; 6 the waiting order; 7 the waiting time of diagnosis and treatment; 8 diagnosis and treatment time; 9 patience of doctors; 10 notification of treatment plan; II patient privacy protection; 12 cleaning and convenience of the toilet; 13 outpatient clinic environment; 14 security measures; 15 medical charges; 16 the waiting time for getting the medicine; 17 the notification of drug usage; 18 service attitude. 


\section{Analysis of the Demographic Factors Affecting Patient Satisfaction}

The population with the highest and lowest satisfaction was selected according to the $80 / 20$ rule. We found that $18.8 \%$ of the respondents scored 41-64 points (lowest satisfaction) and $20.5 \%$ scored $81-90$ points (highest satisfaction). To better understand patient satisfaction according to demographic factors such as age, gender, and education level, we obtained CORs and AORs by implementing univariate and multivariable logistic regression models, respectively.

In the analysis of the lowest score group, both univariate logistic regression models and multivariable logistic regression models showed that age, education level and FPMI were significantly associated with satisfaction. When compared to patients aged $\leq 18$ years, patients aged 19-39 years $(\mathrm{COR}=1.88$ 95\% CI $=1.35-2.62 ; \mathrm{AOR}=1.82$ 95\% CI $=1.30-2.56)$, aged $40-59$ years $(\mathrm{COR}=1.8795 \%$ $=1.32-2.66 ; \mathrm{AOR}=2.0395 \% \mathrm{CI}=1.41-2.92)$ and aged $\geq 60$ $(\mathrm{COR}=1.51 \quad 95 \% \quad \mathrm{CI}=1.00-2.28 ; \quad \mathrm{AOR}=1.76 \quad 95 \%$ $\mathrm{CI}=1.14-2.70)$ were more likely to be dissatisfied with the medical service. In addition, there was a higher proportion of patients with the lowest satisfaction who had a college graduate or above education $(\mathrm{COR}=1.46,95 \%$ $\mathrm{CI}=1.12-1.90 ; \mathrm{AOR}=1.36$ 95\% $\mathrm{CI}=1.03-1.79)$ compared to those with a junior middle graduate or less educational background. More patients with an FPMI $>7000 \mathrm{CNY}$ were detected in the lowest satisfaction group ( $\mathrm{COR}=3.41,95 \%$ $\mathrm{CI}=1.68-6.90 ; \quad \mathrm{AOR}=3.30,95 \% \quad \mathrm{CI}=1.60-6.81)$ than patients with an FPMI $\leq 3000 \mathrm{CNY}$. The results are shown in Table 2.

Analysis of the highest score group showed that age, education level, FPMI, marital status, residence and type of health insurance were significantly associated with satisfaction. The logistic regression models showed that patients aged 19-39 $(\mathrm{COR}=0.62,95 \% \mathrm{CI}=0.48-0.80 ; \mathrm{AOR}=0.63$, 95\% CI $=0.47-0 . \quad 83)$, aged $40-59 \quad(\mathrm{COR}=0.45, \quad 95 \%$ $\mathrm{CI}=0.33-0.61 ; \mathrm{AOR}=0.42,95 \% \mathrm{CI}=0.31-0.58)$ and aged $\geq$ $60 \quad(\mathrm{COR}=0.31, \quad 95 \% \quad \mathrm{CI}=0.21-0.46 ; \quad \mathrm{AOR}=0.26, \quad 95 \%$ $\mathrm{CI}=0.17-0.41)$ were more likely to be satisfied with the medical service than those aged $\leq 18$ years. Respondents who had a high school or technical secondary school education background $\quad(\mathrm{COR}=0.48, \quad 95 \% \quad \mathrm{CI}=0.37-0.63$; $\mathrm{AOR}=0.46,95 \% \mathrm{CI}=0.35-0.61)$ and a college graduate or above $(\mathrm{COR}=0.77,95 \% \mathrm{CI}=0.60-0.99)$ education background were more likely to be satisfied with the medical service than those with a junior middle graduate or less educational background. More patients with an FPMI of 3001-5000 CNY were detected in the highest satisfaction group $(\mathrm{COR}=0.78,95 \% \mathrm{CI}=0.62-0.98 ; \mathrm{AOR}=0.76,95 \%$ $\mathrm{CI}=0.60-0.96)$ than those with an FPMI $\leq 3000 \mathrm{CNY}$. Nonlocal patients $(\mathrm{COR}=1.40,95 \% \mathrm{CI}=1.03-1.90 ; \mathrm{AOR}=1.48$, $95 \% \mathrm{CI}=1.07-2.04)$ and unmarried patients $(\mathrm{COR}=1.43$, 95\% $\mathrm{CI}=1.15-1.77$ ) were more likely to be satisfied with medical service. When compared to those with the medical insurance for urban residents, patients with no health insurance $(\mathrm{COR}=1.41,95 \% \mathrm{CI}=1.07-1.86)$ and patients with medical insurance for urban workers $(\mathrm{AOR}=1.74,95 \%$ $\mathrm{CI}=1.27-2.39)$ were detected in the highest satisfaction group. The results are shown in Table 3.

\section{Discussion}

The medical doctor-patient relationship in China is facing serious challenges, and an ever-increasing number of conflict events between medical staff and patients have been reported, which triggered increased rates of patient dissatisfaction. ${ }^{34-38}$ This study, however, found that "the patience of doctors" and "patients' privacy protection" and "service attitude" showed a relatively high level of satisfaction and a relatively high degree of influence. The findings indicated that outpatient satisfaction with doctors' patience, service attitude and patient privacy protection had gradually improved. The aspects are always important factors of patient satisfaction that have received increasing attention by patients. ${ }^{11}$ In response to the severity of the conflict between medical staff and patients, the Chinese government carried out the "Action Plan for Further Improving Medical Services". The action plan aimed to improve medical services and patient satisfaction, which included paying more attention to humanistic care, building a harmonious medical doctor-patient relationship, strengthening the protection of patient privacy and improving service attitude. ${ }^{39}$ The Chinese Health Management Department also established clear assessment criteria to evaluate the effect. Research has shown that these policies have achieved much. ${ }^{11}$ This explains why the degree of outpatient satisfaction with the doctor's patience and service attitude and patient privacy protection was relatively high among the whole scale of outpatient satisfaction.

Our study found that outpatients showed a relatively high degree of satisfaction with "the waiting time for registration" and "the waiting time for payment", which tended to become the advantages of comprehensive hospitals. With the widespread use of mobile medical apps and other information technologies in medical institutions, 
Table 2 Logistic Regression Analysis of Influencing Factors Associated with Patient Satisfaction (for Lowest Score Group) (N=2109)

\begin{tabular}{|c|c|c|c|c|c|}
\hline Variables & Demographic Characteristics & $\begin{array}{l}\text { Scored } 41-64 \\
(n=396,18.8 \%)\end{array}$ & $\begin{array}{l}\text { Scored } 65-90 \\
(n=17 \mid 3,81.2 \%)\end{array}$ & $\begin{array}{l}\text { Crude OR } \\
(95 \% \mathrm{Cl})\end{array}$ & $\begin{array}{l}\text { Adjusted OR } \\
(95 \% \mathrm{Cl})\end{array}$ \\
\hline Gender & $\begin{array}{l}\text { Male } \\
\text { Female }\end{array}$ & $\begin{array}{l}158(18.79) \\
238(18.77)\end{array}$ & $\begin{array}{l}683(81.21) \\
1030(81.23)\end{array}$ & $1.00(0.80-1.25)$ & $1.03(0.81-1.32)$ \\
\hline Age(years) & $\begin{array}{l}\leq 18 \\
19-39 \\
40-59 \\
\geq 60\end{array}$ & $\begin{array}{l}54(12.41) \\
176(21.08) \\
114(20.96) \\
52(17.63)\end{array}$ & $\begin{array}{l}381(87.59) \\
659(78.92) \\
430(79.04) \\
243(82.37)\end{array}$ & $\begin{array}{l}1.88(1.35-2.62)^{\mathrm{a}} \\
1.87(1.32-2.66)^{\mathrm{a}} \\
1.51(1.00-2.28)^{\mathrm{b}}\end{array}$ & $\begin{array}{l}1.82(1.30-2.56)^{\mathrm{a}} \\
2.03(1.41-2.92)^{\mathrm{a}} \\
1.76(1.14-2.70)^{\mathrm{b}}\end{array}$ \\
\hline Education level & $\begin{array}{l}\text { Junior middle graduate or less } \\
\text { High school or technical secondary school } \\
\text { College graduate or above }\end{array}$ & $\begin{array}{l}132(16.48) \\
123(18.14) \\
141(22.38)\end{array}$ & $\begin{array}{l}669(83.52) \\
555(81.86) \\
489(77.62)\end{array}$ & $\begin{array}{l}1.12(0.86-1.47) \\
1.46(1.12-1.90)^{c}\end{array}$ & $\begin{array}{l}1.05(0.80-1.39) \\
1.36(1.03-1.79)^{b}\end{array}$ \\
\hline Marital status & $\begin{array}{l}\text { Married } \\
\text { Unmarried }\end{array}$ & $\begin{array}{l}263(19.5) \\
133(17.5)\end{array}$ & $\begin{array}{l}1086(80.5) \\
627(82.5)\end{array}$ & $0.88(0.70-1.10)$ & $1.03(0.81-1.32)$ \\
\hline $\operatorname{FPMY}(\mathrm{CNY})$ & $\begin{array}{l}\leq 3000 \\
3001-5000 \\
5001-7000 \\
>7000\end{array}$ & $\begin{array}{l}153(17.04) \\
192(19.49) \\
37(19.27) \\
14(41.18)\end{array}$ & $\begin{array}{l}475(82.96) \\
793(80.51) \\
155(80.73) \\
20(58.82)\end{array}$ & $\begin{array}{l}1.18(0.93-1.49) \\
1.16(0.78-1.73) \\
3.41(1.68-6.90)^{\mathrm{a}}\end{array}$ & $\begin{array}{l}1.13(0.88-1.44) \\
1.13(0.75-1.70) \\
3.30(1.60-6.81)^{c}\end{array}$ \\
\hline Rsidence & $\begin{array}{l}\text { Local } \\
\text { Nonlocal }\end{array}$ & $\begin{array}{l}349(18.72) \\
47(19.18)\end{array}$ & $\begin{array}{l}1515(81.28) \\
198(80.82)\end{array}$ & $1.03(0.73-1.45)$ & $0.91(0.65-1.30)$ \\
\hline Type of health insurance & $\begin{array}{l}\text { MIUR } \\
\text { MIUW } \\
\text { CMI } \\
\text { Other } \\
\text { No health insurance }\end{array}$ & $\begin{array}{l}111(17.73) \\
79(15.99) \\
14(26.42) \\
69(22.7) \\
123(19.46)\end{array}$ & $\begin{array}{l}515(82.27) \\
415(84.01) \\
39(73.58) \\
235(77.3) \\
509(80.54)\end{array}$ & $\begin{array}{l}0.88(0.64-1.21) \\
1.67(0.87-3.17) \\
1.36(0.97-1.91) \\
1.12(0.84-1.49)\end{array}$ & $\begin{array}{l}0.76(0.55-1.05) \\
1.64(0.85-3.17) \\
1.35(0.96-1.90) \\
1.13(0.85-1.52)\end{array}$ \\
\hline
\end{tabular}

Notes: ${ }^{\mathrm{a}} \mathrm{p}<0.00,{ }^{\mathrm{b}} \mathrm{p}<0.05,{ }^{\mathrm{c}} \mathrm{p}<0.01$.

Abbreviations: FPMI, family per-capita monthly income; MIUR, medical insurance for urban residents; MIUW, medical insurance for urban workers; CMI, commercial medical insurance; OR, odds ratio; $\mathrm{Cl}$, confidence interval.

patients had a variety of registration and payment methods (including WeChat official accounts, smart phones, automatic teller machine "ATM"-based methods, selfregistration and medical institution payment machines) that are gradually replacing the traditional process. ${ }^{40}$ The application of mobile medical apps could be time-saving for patients throughout their visits, avoiding queueing up for payment. Therefore, the problems of registration difficulty and slow payment have been alleviated. ${ }^{17}$ It has been confirmed that patients' medical experiences have been improved to some extent by mobile health apps and other information technologies in medical institutions. Other study also found that patients who appointed by advanced information and communication technology showed a relatively high degree of the overall patient satisfaction than those without an appointment. ${ }^{41}$

Moreover, the "guiding services", "accuracy of guidance facilities" and "waiting order" showed relatively higher degrees of influence and satisfaction in the matrix. The tertiary hospitals are representative of high-quality health resources in China. Central and local governments financially invest in buildings, equipment, and medical facilities for tertiary hospitals to a great extent. There is no doubt that comprehensive hospitals have relatively complete supporting facilities and logistics management systems. $^{42}$ The pre-diagnosis counters, diagnosis area, and waiting area before diagnosis were established in the most comprehensive hospital outpatient departments. ${ }^{43}$ These measures could ensure a good patient flow.

Although much achievement has been gained in the medical services since the new medical reform, our results indicated that there is still much to be improved. The new round of medical reform introduced a series of policies, such as building regional medical consortium and initiating the community-first treatment and two-way referral systems to establish the NHMS. ${ }^{6}$ They are intended to alleviate the burden of tertiary hospitals via maximizing medical resources and delivering patients to basic-level hospitals; however, this has not been well achieved to date. $^{44}$ According to a large study, the proportion of 
Table 3 Logistic Regression Analysis of Influencing Factors Associated with Patient Satisfaction (for Highest Score Group) (N=2।09)

\begin{tabular}{|c|c|c|c|c|c|}
\hline Variables & Demographic Characteristics & $\begin{array}{l}\text { Scored } 81-90 \\
(n=433,20.5 \%)\end{array}$ & $\begin{array}{l}\text { Scored } 41-80 \\
(n=1676,79.5 \%)\end{array}$ & $\begin{array}{l}\text { Crude OR } \\
(95 \% \mathrm{Cl})\end{array}$ & $\begin{array}{l}\text { Adjusted OR } \\
(95 \% \mathrm{Cl})\end{array}$ \\
\hline Gender & $\begin{array}{l}\text { Male } \\
\text { Female }\end{array}$ & $\begin{array}{l}170(20.21) \\
263(20.74)\end{array}$ & $\begin{array}{l}671(79.79) \\
1005(79.26)\end{array}$ & $1.03(0.83-1.28)$ & $1.01(0.81-1.27)$ \\
\hline Age(years) & $\begin{array}{l}\leq 18 \\
19-39 \\
40-59 \\
\geq 60\end{array}$ & $\begin{array}{l}132(30.34) \\
177(21.20) \\
89(16.36) \\
35(11.86)\end{array}$ & $\begin{array}{l}303(69.66) \\
658(78.80) \\
455(83.64) \\
60(88.14)\end{array}$ & $\begin{array}{l}0.62(0.47-0.80)^{\mathrm{a}} \\
0.45(0.33-0.61)^{\mathrm{a}} \\
0.31(0.21-0.46)^{\mathrm{a}}\end{array}$ & $\begin{array}{l}0.63(0.47-0.83)^{\mathrm{b}} \\
0.42(0.31-0.58)^{\mathrm{a}} \\
0.26(0.17-0.4 \mathrm{I})^{\mathrm{a}}\end{array}$ \\
\hline Education level & $\begin{array}{l}\text { Junior middle graduate or less } \\
\text { High school or technical secondary } \\
\text { school } \\
\text { College graduate or above }\end{array}$ & $\begin{array}{l}205(25.60) \\
96(14.20) \\
132(21.00)\end{array}$ & $\begin{array}{l}596(74.40) \\
582(85.80) \\
498(79.00)\end{array}$ & $\begin{array}{l}0.48(0.37-0.63)^{\mathrm{a}} \\
0.77(0.60-0.99)^{\mathrm{c}}\end{array}$ & $\begin{array}{l}0.46(0.35-0.61)^{\mathrm{a}} \\
0.77(0.59-1.01)\end{array}$ \\
\hline Marital status & $\begin{array}{l}\text { Married } \\
\text { Unmarried }\end{array}$ & $\begin{array}{l}248(18.38) \\
185(24.34)\end{array}$ & $\begin{array}{l}1101(81.62) \\
575(75.66)\end{array}$ & $1.43(1.15-1.77)^{\mathrm{b}}$ & $1.15(0.91-1.46)$ \\
\hline $\operatorname{FPMY}(\mathrm{CNY})$ & $\begin{array}{l}\leq 3000 \\
300 I-5000 \\
500 I-7000 \\
>7000\end{array}$ & $\begin{array}{l}201(22.38) \\
181(18.38) \\
46(23.96) \\
5(14.71)\end{array}$ & $\begin{array}{l}697(77.62) \\
804(81.62) \\
146(76.04) \\
29(85.29)\end{array}$ & $\begin{array}{l}0.78(0.62-0.98)^{c} \\
1.09(0.76-1.58) \\
0.60(0.23-1.56)\end{array}$ & $\begin{array}{l}0.76(0.60-0.96)^{c} \\
1.00(0.68-1.47) \\
0.48(0.18-1.29)\end{array}$ \\
\hline Rsidence & $\begin{array}{l}\text { Local } \\
\text { Nonlocal }\end{array}$ & $\begin{array}{l}370(19.85) \\
63(25.71)\end{array}$ & $\begin{array}{l}1494(80.15) \\
182(74.29)\end{array}$ & $1.40(1.03-1.90)^{\mathrm{c}}$ & $1.48(1.07-2.04)^{c}$ \\
\hline Type of health insurance & $\begin{array}{l}\text { MIUR } \\
\text { MIUW } \\
\text { CMI } \\
\text { Other } \\
\text { No health insurance }\end{array}$ & $\begin{array}{l}110(17.57) \\
106(21.46) \\
11(20.75) \\
60(19.74) \\
146(23.10)\end{array}$ & $\begin{array}{l}516(82.43) \\
388(78.54) \\
42(79.25) \\
244(80.26) \\
486(76.90)\end{array}$ & $\begin{array}{l}1.28(0.95-1.73) \\
1.23(0.61-2.46) \\
1.15(0.81-1.64) \\
1.41(1.07-1.86)^{c}\end{array}$ & $\begin{array}{l}1.74(1.27-2.39)^{c} \\
1.29(0.63-2.64) \\
1.17(0.82-1.68) \\
1.30(0.98-1.74)\end{array}$ \\
\hline
\end{tabular}

Notes: ${ }^{\mathrm{a}} \mathrm{p}<0.00,{ }^{\mathrm{b}} \mathrm{p}<0.01,{ }^{\mathrm{c}} \mathrm{p}<0.05$.

Abbreviations: FPMI, family per-capita monthly income; MIUR, medical insurance for urban residents; MIUW, medical insurance for urban workers; CMI, commercial medical insurance; OR, odds ratio; $\mathrm{Cl}$, confidence interval.

referral patient in the terminal survey did not change too much from the baseline level. ${ }^{41}$ The siphon effect by large hospitals for grassroots medical resources has not been contained, and the phenomenon that "tertiary hospitals are overcrowded and basic-level hospitals are empty" has not been improved. These results found that patients needed long time to wait for treatment, short treatment time and medical charges that were too expensive in the content areas that need urgent improvement by medical institutions. These aspects showed the highest degrees of influence but earned the lowest level of satisfaction. Our findings indicated that the difficulty and expense of getting medical services were still the two major factors affecting the satisfaction of patients in China.

We found that the difficulty in getting medical service has two phenomena: one was the long waiting time between the appointment and healthcare seeking, and another one was the short visit time for each patient to be diagnosed and treated. ${ }^{45}$ This phenomenon could be explained by crowded tertiary hospitals, which were consistent with other studies. ${ }^{11,16,46}$ At the end of 2018, the total number of medical visits was 8.31 billion, including 3.58 billion in hospitals $(43.1 \%)$ and 4.41 billion in basic-level medical institutions (53.1\%). Compared to last year, the counterparts in hospitals increased by 140 million and that in basic-level medical institutions decreased by 20 million. ${ }^{47}$ There are so many outpatients with long waiting time, and doctors have to shorten diagnosis time available to patients; the average minimum diagnosis and treatment time for every patient is only 10 mins. ${ }^{48}$ Thus, patients do not have enough time to communicate with medical staff about their medical needs, feelings and expectations, resulting in a lower level of satisfaction with the medical service. A strong inverse relationship between patient satisfaction and waiting time has been also demonstrated by many studies. ${ }^{49-52}$ Therefore, there was room for improvement for referral patients as well as in the dual-referral system. 
Which makes it possible for doctors to spend more energy on patients to improve their experience.

Additionally, primary medical institutions may not be equipped with advanced medical resources, including technicians and health professionals; such situations may drive health-seeking behavior towards tertiary hospitals rather than towards the potentially more appropriate primary health care facilities. ${ }^{53,54}$ Therefore, more preferential policies and financial support should be given to primary medical institutions to address these problems. We will strengthen the ranks of community-level medical and health professionals, especially GPs. ${ }^{55}$

Moreover, the study by Liu et al showed that, while Chinese outpatients may lack knowledge of the NHMS, most patients hold a positive attitude towards the establishment of the NHMS. Even so, in regard to seeking health care in a hierarchical system, the continued hesitancy of the majority of patients indicates the need for policy makers to take action to improve public awareness of the NHMS. ${ }^{7,8}$ Therefore, local government could cooperate with the GPs, family doctors and other professionals to conduct health education and to guide residents to form a scientific view of medical treatment, building the "minor illness in the community, serious illness to the hospital, rehabilitation back to the community" medical model.

In line with other studies, we also noticed that another foremost factor contributing to low outpatient satisfaction was "medical charges are too expensive". This finding indicated the problem that obtaining medical services became expensive. ${ }^{17}$ In response to this situation, the local government also launched related policies, including provincial-level pooled tendering and procurement and a "zeromarkup" (ie, no-profit) policy for medicines on the new National Essential Drugs List at the grassroots level to lower the drug prices. ${ }^{3}$ The basic medical insurance system was improved, government subsidies for basic medical insurance for urban and rural residents were raised to $520 \mathrm{RMB}$, and serious illness insurance increased by $15 \mathrm{RMB}^{56}$ Medical insurance payment methods are moving away from fee-for-services towards more scientific methods, including case-mix, capitation, and global budgeting. ${ }^{2,57}$ Although these policies have greatly alleviated the financial burden caused by medical costs, there is still space for improvement. ${ }^{58}$ This explains why outpatient satisfaction with medical costs was at a lower level.

However, one interpretation could be to acknowledge that medical charges have always been a sensitive item. Patients always have high expectations for better medical quality, including low medical charges, which easily results in dissatisfaction. Patient expectations were associated with patient satisfaction. ${ }^{59,60}$ Therefore, regardless of the level of current medical charges, it was difficult for patients to feel satisfaction premised on current medical charges. This may also explain why medical charges are always one of the foremost reasons for dissatisfaction. In other words, alleviating the financial burden from healthcare consumption could play an important role in improving patient satisfaction, which requires the continuous attention of health management departments.

Using the $80 / 20$ rule, we investigated whether there were patterns in the demographic information of respondents in the lowest and highest score groups, such that we may identify population groups that the managers of hospitals should especially focus on. It was found that patients with an FPMI between 3001-5000 CNY were more likely to be satisfied with medical service than those with an income below 3000 CNY. Patients with an FPMI above $7000 \mathrm{CNY}$ had a lower satisfaction than those with an income below $3000 \mathrm{CNY}$. This is probably because lowincome outpatients tend to have lower expectations, they only want effective treatment and quick recovery from disease. Conversely, high-income outpatients have higher expectations, and they always expect high levels of medical service, which easily leads to a poor experience and a lower degree satisfaction. ${ }^{61}$

It was shown that patients with higher levels of education tended to have higher levels of satisfaction with medical services. This finding indicated that these patients have a better understanding of medical policy and knowledge. ${ }^{62,63}$ This study also found that the results of satisfaction among those with a college education and above were divided into two extremes: the most satisfied patients were those with a college education or above and the same was the case for the least satisfied patients. This is probably because those with a high level of education have an increased recognition of things. When they are asked to evaluate medical services, they will make relatively clear judgments based on their own knowledge and feelings and tend to give good or bad results, while patients with low levels of education may give vague evaluations such as "average" and "general".

This study showed that nonlocal patients showed higher levels of satisfaction. ${ }^{64}$ These patients may have a better impression of the hospital because they chose the hospital for its merits, so they would be more likely to be satisfied with medical service. 
It was also found that patients with medical insurance for urban workers have higher satisfaction than those with other types of health insurance. Under the current health insurance policy in China, the reimbursement levels and benefit packages of medical insurance for urban workers are relatively higher. ${ }^{65}$ and the main insured persons are urban workers who have better economic situations, so they earned higher satisfaction with medical charges. Inequity issues and dissatisfaction with current integration reform of health insurance schemes still exist. ${ }^{52,66}$ Therefore, more government subsidies for low-income residents, rural residents and less-developed regions could be taken into account to improve the performance of the ongoing integration reforms.

\section{Limitation}

The current study has a number of limitations. First, due to the large fluidity of patients in the outpatient setting, there is not a complete visit record, so the survey did not have strict random sampling. Second, our study was a crosssectional survey, so the changes over time could not be examined. Third, the children under 12 were represented or consented by parents or legal guardians may cause some biases. In future relevant studies, we should distinguish the differences between patients and their guardians to minimize the biases.

\section{Conclusion}

In conclusion, this study found that the current outpatient satisfaction in comprehensive hospitals needs further improvement. The difficulty and expense of obtaining medical services are still the two major factors affecting the satisfaction of patients. We suggest that the "long time to wait for treatment", "short treatment time", and "medical charges too expensive" are the primary areas for improvement. Outpatient sociodemographic characteristics, including education level, income level, residence and type of health insurance, were chiefly responsible for outpatient satisfaction. The hospital administrators could obtain valuable information from these factors and improve the quality of medical services, thus improving patient satisfaction.

\section{Acknowledgments}

This project was supported by the National Natural Science Foundation of China (71774049) and the Talent Funding Program of Hubei University of Medicine (2017QDJRW10).

\section{Disclosure}

The authors report no conflicts of interest in this work.

\section{References}

1. Husain L. Policy experimentation and innovation as a response to complexity in China's management of health reforms. Global Health. 2017;13:54. doi:10.1186/s12992-017-0277-x

2. Jing L, Chen R, Jing L, et al. Development and enrolee satisfaction with basic medical insurance in China: a systematic review and stratified cluster sampling survey. Int $J$ Health Plann Manage. 2017;32:285-298. doi:10.1002/hpm.v32.3

3. Yang M, Li Q, Pan J, et al. Effects of the essential medicine policy in China on outpatient service use and medicine cost: a secondary analysis of 5 year panel data. Lancet. 2015;386:S28. doi:10.1016/ S0140-6736(15)00606-6

4. Chen R, Jing L, Xu J, et al. Satisfaction with basic medical insurance in China: a stratified cluster sampling survey. Lancet. 2016;388:S14. doi:10.1016/S0140-6736(16)31941-9

5. Li X, Lu J, Hu S, et al. The primary health-care system in China. Lancet. 2017;390:2584. doi:10.1016/S0140-6736(17)33109-4

6. Zhao R, Li Y, Liu C, et al. Effects of the integrated healthcare delivery system on 270 pilot cities in 2016: a mixed methods study. Lancet. 2017;390:S101. doi:10.1016/S0140-6736(17)33239-7

7. Liu X, Hou Z, Towne SD Jr, et al. Knowledge, attitudes, and practices related to the establishment of the National Hierarchical Medical System (NHMS) among outpatients in Chinese tertiary hospitals. Medicine. 2018;97:e11836. doi:10.1097/MD.000000000 0011836

8. Liu X, Tan A, Mao Z, et al. Awareness of the role of general practitioners in primary care among outpatient populations: evidence from a cross-sectional survey of tertiary hospitals in China. $B M J$ Open. 2018;8:e020605. doi:10.1136/bmjopen-2017-020605

9. Ahmed F, Burt J, Roland M. Measuring patient experience: concepts and methods. Patient Patient Centered Outcomes Res. 2014;7 (3):235-241. doi:10.1007/s40271-014-0060-5

10. Lyu H, Wick EC, Housman M, Freischlag JA, Makary MA. Patient satisfaction as a possible indicator of quality surgical care. JAMA Surg. 2013;148:362-367. doi:10.1001/2013.jamasurg.270

11. Guangyu H, Laiyang W, Jing S, et al. Survey of patient satisfaction with ambulatory services at 136 hospitals in China. Chin J Hosp Administration. 2016;32:423-427.

12. Linghan S, Ye L, Ding D, et al. Patient satisfaction with hospital inpatient care: effects of trust, medical insurance and perceived quality of care. PLoS One. 2016;11:e0164366. doi:10.1371/journal. pone. 0164366

13. National Health and Family Planning Commission of the People's Republic of China notice on printing and issuing action plan for further improving medical services. Available from: http://www. nhfpc.gov.cn/yzygj/s3593g/201501/5584853cfa254d1aa4e38 de0700891fa.shtml.Accessed March 13, 2018.

14. Pan J, Liu D, Ali S. Patient dissatisfaction in China: what matters. Soc Sci Med. 2015;143:145-153. doi:10.1016/j.socscimed.2015.08. 051

15. Zhang L, Chen H, Li M, et al. Factors influencing inpatients' satisfaction with hospitalization service in public hospitals in Shanghai, People's Republic of China. Patient Prefer Adherence. 2016;10:469-477. doi:10.2147/PPA.S98095

16. Yu W, Li M, Xue C, et al. Determinants and influencing mechanism of outpatient satisfaction: a survey on tertiary hospitals in the People's Republic of China. Patient Preference Adherence. 2016;10:601-612.

17. Xie J, Hu Y, Lu C. Factors associated with outpatient experience of Chinese public hospitals: a cross-sectional study. Lancet. 2017;390: S38. doi:10.1016/S0140-6736(17)33176-8 
18. Xesfingi S, Karamanis D. In- and out-patient satisfaction assessment: the case of a Greek general hospital. Mpra Paper. 2015.

19. Hussain A, Asif M, Jameel A, et al. Measuring OPD patient satisfaction with different service delivery aspects at public hospitals in Pakistan. Int J Environ Res Public Health. 2019;16(13):2340. doi:10.3390/ijerph16132340

20. Alrasheedi KF, Al-Mohaithef M, Edrees HH, et al. The association between wait times and patient satisfaction: findings from primary health centers in the Kingdom of Saudi Arabia. Health Serv Res Managerial Epidemiol. 2019;6:1-7. doi:10.1177/2333392819861246

21. Galea VP, Rojanasopondist P, Connelly JW, et al. Changes in patient satisfaction following total joint arthroplasty. $J$ Arthroplasty. 2019;16:2340.

22. Lyu H, Wick EC, Housman M, Freischlag JA, Makary MA. Patient satisfaction as a possible indicator of quality surgical care. JAMA Surg. 2013;148:362-367. doi:10.1001/2013.jamasurg.270

23. Shrestha N, Mongkolchati A, Rattanapan C, Wongsawass S. Assessment of patient satisfaction at a traditional medicine hospital in Nepal. J Pub Health Dev. 2012;10:17-29.

24. Berhane A, Enquselassie F. Patient expectations and their satisfaction in the context of public hospitals. Patient Prefer Adherence. 2016;10:1919-1928.

25. Linghan S, Ye L, Ding D, et al. Patient satisfaction with hospital inpatient care: effects of trust, medical insurance and perceived quality of care. PLoS One. 2016;11:e0164366. doi:10.1371/journal. pone. 0164366

26. Mekonen T, Yimer S, Yohannis Z, et al. Satisfaction and associated factors of outpatient psychiatric service consumers in Ethiopia. Patient Prefer Adherence. 2016;10:1847-1852.

27. Kim CE, Shin J-S, Lee J, et al. Quality of medical service, patient satisfaction and loyalty with a focus on interpersonal-based medical service encounters and treatment effectiveness: a cross-sectional multicenter study of complementary and alternative medicine (CAM) hospitals. BMC Complement Altern Med. 2017;17:174. doi:10.1186/s12906-017-1691-6

28. Asif M, Jameel A, Sahito N, et al. Can leadership enhance patient satisfaction? assessing the role of administrative and medical quality. Int J Environ Res Public Health. 2019;16:3212. doi:10.3390/ ijerph16173212

29. Statistical communique on national economic and social development of Shiyan city in 2018. Available from: http://www.shiyan.gov.cn/ sysgovinfo/stjj/sfgwgkml/tjxx_1423/tjgb_1425/201904/t20190402_ 1694470.shtml. Accessed April 5, 2019.

30. Raharjo H, Guglielmetti Mugion R, Di Pietro L. et al. Do satisfied employees lead to satisfied patients? An empirical study in an Italian hospital. Total Qual Manage Bus Excellence;2016. 1-22. doi:10.1080/14783363.2016.1190641

31. Rahmani Z, Ranjbar M, Nadi Gara A, et al. The study of the relationship between value creation and customer loyalty with the role of trust moderation and customer satisfaction in Sari hospitals. Electron Physician. 2017;9:4474-4478. doi:10.19082/4474

32. Yu MC. Multi-criteria ABC analysis using artificial-intelligencebased classification techniques. Expert Syst Appl. 2011;38:3416-3421. doi:10.1016/j.eswa.2010.08.127

33. Chunxiao H. Third-Party Evaluation of Patient Satisfaction in Public Hospitals in Chongqing. Chongqing Medical University; 2015.

34. Pan K, Jing F, Dongmei W, et al. A third-party investigation of inpatient satisfaction with a tertiary hospital in People's Republic of China. Patient Prefer Adherence. 2018;12:2027-2037. doi:10.2147/ PPA.S176471

35. Jing S, Jun W, Shiyang L, et al. The impact of adverse media reporting on doctor-patient relationships in China: an analysis with propensity-score matching. Lancet. 2017;390:S100. doi:10.1016/ S0140-6736(17)33238-5

36. Jin T. A transformative tale of patients and doctors in China. Lancet. 2011;377:1144. doi:10.1016/S0140-6736(11)60451-0
37. Wang G, Xie J, Hu Y. Doctor-outpatient communications in Chinese public hospitals: a cross-sectional survey. Lancet. 2016;388:S38. doi:10.1016/S0140-6736(16)31965-1

38. Chinese doctor practice status white paper [homepage on the Internet] Beijing: Chinese medical doctor association; 2015 [updated May 28, 2015]. Available from: http://www.cmda.net/zlwqtzgg/ 10578.jhtml. Accessed September 3, 2018.

39. National health commission of the People's Republic of China. The circular on the issuance of the action plan for further improvement of medical services (2018-2020). Available from: http://www.nhc.gov. cn/. Accessed March 18, 2019.

40. Xie J, Hu Y, Wang G, et al. Effect of a mobile medical app on outpatient experience: a cross-sectional study. Lancet. 2017;390: S65. doi:10.1016/S0140-6736(17)33203-8

41. Hu G, Chen Y, Liu Q, et al. Patient experience of hospital care in china: major findings from the Chinese patient experience questionnaire survey (2016-2018). BMJ Open. 2019;9(9):e031615. doi:10.1136/bmjopen-2019-031615

42. Xinyu Z, Lin Z, Zhuang C, et al. Study on equity and efficiency of health resources and services based on key indicators in China. PLoS One. 2015;10:e0144809. doi:10.1371/journal.pone.0144809

43. Zhang QJ, Li M, Zhou Y, Wan XX, Zhou XM. Improving the influence of pre-diagnosis services on outpatient satisfaction. Med Inform. 2015;28:28.

44. Fen FL, Wu ZJ, Cai YP, Guo Q. Current situation and development strategy of "diagnosis and treatment registration in community". Health Econ Res. 2014;5:010.

45. Sun J, Lin Q, Zhao P, et al. Reducing waiting time and raising outpatient satisfaction in a Chinese public tertiary general hospital-an interrupted time series study. BMC Public Health. 2017;17:668. doi:10.1186/s12889-017-4667-z

46. Shrestha N, Mongkolchati A, Rattanapan C, et al. Assessment of patient satisfaction at a traditional medicine hospital in Nepal. J Pub Health Dev. 2012;10:17-29.

47. The statistical bulletin on health development in China in 2018 . Available from: http://www.nhc.gov.cn/guihuaxxs/s10748/201905/ 9b8d52727cf346049de8acce25ffcbd0.shtml. Accessed May 22, 2019.

48. Wu JJ [webpage on the Internet]. Ensure at least 10 minutes for doctor-patient communication; 2013. Available from: http://epaper. dfdaily.com/dfzb/html/2013-12/12/content_845288.htm.

49. Michael M, Schaffer SD, Egan PL, et al. Improving wait times and patient satisfaction in primary care. J Healthc Qual. 2013;35 (2):50-60. doi:10.1111/jhq.12004

50. Katre AN. Assessment of the correlation between appointment scheduling and patient satisfaction in a pediatric dental setup. Int J Dent. 2014;2014:1-7. doi:10.1155/2014/453237

51. Pitrou I, Lecourt AC, Bailly L, et al. Waiting time and assessment of patient satisfaction in a large reference emergency department: a prospective cohort study, France. Eur $J$ Emerg Med. 2009;16:177-182. doi:10.1097/MEJ.0b013e32831016a6

52. Preyde M, Crawford K, Mullins L. Patients' satisfaction and wait times at Guelph general hospital emergency department before and after implementation of a process improvement project. CJEM. 2012;14(3):157-168. doi:10.2310/8000.2012.110590

53. Jiang Q, Lang J, Cai J, et al. Avoidable hospital admissions and resource use in China: an exploratory analysis of 2.57 million hospital admissions. Lancet. 2015;386:S25- S25. doi:10.1016/S01406736(15)00603-0

54. Qunhong S, Liyang T, Yilin F, et al. The imbalance between patient needs and the limited competence of top-level health providers in Urban China: an empirical study based on a 2008 national household survey. SSRN Electron J. 2010.

55. Cheng Z, Cai M, Tao H, et al. Efficiency and productivity measurement of rural township hospitals in China: a bootstrapping data envelopment analysis. BMJ Open. 2016;6:e011911. doi:10.1136/ bmjopen-2016-011911 
56. The circular on ensuring basic medical care for urban and rural residents in 2019. Available from: http://www.nhsa.gov.cn/art/2019/ 5/13/art_37_1286.html. Accessed April 26, 2019.

57. Junxiang L, Jingzi XU, Tianyu Z, et al. Ethical reflections on the equity of the current basic health insurance system reform in China: a case study in hunan province. Cambridge $Q$ Healthcare Ethics. 2018;27:447-458. doi:10.1017/S0963180117000834

58. He AJ, Wu S. Towards universal health coverage via social health insurance in China: systemic fragmentation, reform imperatives, and policy alternatives. Appl Health Econ Health Policy. 2017;15:707-716. doi:10.1007/s40258-016-0254-1

59. Bjertnaes OA, Sjetne IS, Iversen $\mathrm{HH}$. Overall patient satisfaction with hospitals: effects of patient-reported experiences and fulfilment of expectations. BMJ Qual Saf. 2012;21:39-46. doi:10.1136/bmjqs2011-000137

60. Berhane MA, Fikre E. Patient expectations and their satisfaction in the context of public hospitals. Patient Prefer Adherence. 2016;10:1919-1928.

61. Liu X, Lu H, Wang Y, et al. Factors affecting patient satisfaction with ecdemic medical care: a cross-sectional study in Nanchang, China. Patient Prefer Adherence. 2018;12:1373-1382. doi:10.2147/PPA. S167244
62. Baltaci D, Eroz R, Ankarali H. Association between patients' sociodemographic characteristics and their satisfaction with primary health care services in Turkey. J Kuwait Med Assoc. 2013;45:291-299.

63. Al-Borie HM, Damanhouri AM. Patients' satisfaction of service quality in Saudi hospitals: a SERVQUAL analysis. Int $J$ Health Care Qual Assur. 2013;26:20-30. doi:10.1108/09526861311288613

64. Levinton C, Veillard J, Slutsky A, Brown A. The importance of place of residence in patient satisfaction. Int $J$ Qual Health Care. 2011;23:495-502. doi:10.1093/intqhe/mzr048

65. Wang C, Rao K, Wu S, Liu Q. Health care in China: improvement, challenges, and reform. Chest. 2013;143:524-531. doi:10.1378/chest.121839

66. Shan L, Zhao M, Ning N, et al. Dissatisfaction with current integration reforms of health insurance schemes in China: are they a success and what matters? Health Policy Plan. 2018;33:345-354. doi:10.1093/heapol/czx173
Patient Preference and Adherence

\section{Publish your work in this journal}

Patient Preference and Adherence is an international, peer-reviewed, open access journal that focusing on the growing importance of patient preference and adherence throughout the therapeutic continuum. Patient satisfaction, acceptability, quality of life, compliance, persistence and their role in developing new therapeutic modalities and compounds to optimize clinical outcomes for existing disease

\section{Dovepress}

states are major areas of interest for the journal. This journal has been accepted for indexing on PubMed Central. The manuscript management system is completely online and includes a very quick and fair peer-review system, which is all easy to use. Visit http:// www.dovepress.com/testimonials.php to read real quotes from published authors. 